\title{
PEDESTRIAN LEVEL OF SERVICE: THE IMPACT OF SOCIAL GROUPS ON PEDESTRIAN FLOW CHARACTERISTICS
}

\author{
ELVEZIA M. CEPOLINA ${ }^{1}$, FEDERICO MENICHINI ${ }^{1} \&$ PALOMA GONZALEZ ROJAS ${ }^{2}$ \\ ${ }^{1}$ University of Pisa, Department of Civil and Industrial Engineering. \\ ${ }^{2}$ Massachusetts Institute of Technology, Department of Architecture.
}

\begin{abstract}
A comprehensive measure of the level of pedestrian comfort can lead to an improved design of public spaces, to the appropriate dimensioning of urban infrastructure (such as airports, stations and commercial centers), and, most importantly, to a design that is more responsive to people and to that very fundamental human activity: walking.

The planning and design of the pedestrian environment is based on pedestrian Levels of Service (LOS). These levels currently classify the level of comfort based on space available for movement and speed (and delay, in case of crosswalks). Guidance is provided for different area types and times of day. Although many methods of assessing pedestrian LOS have been developed, all these do not consider spontaneous pedestrian groups. However, social groups, such as friends, couples, colleagues and families, represent an important component of urban crowds.

The paper presents first, an overview of the current methods for assessing pedestrian environment LOS. Then the paper presents the application of the HCM method for the evaluation of a selected site LOS. The calculation is based on collected measurements of pedestrian flow. Some critical issues and inconsistencies result. These have been reviewed and read taking into account the presence of groups in pedestrian flows.

Keywords: pedestrian groups, pedestrian level of service.
\end{abstract}

\section{INTRODUCTION}

Walking is one of the main important transportation mode, cheap, zero pollution and healthy, to be strongly improved for sustainable cities development, bringing wider economic and community benefits; it also is the means for moving in many urban facilities as buildings, airports, stations, shopping malls, city shopping 'natural area', museums, etc.

Since the late nineties, bicycling and walking have received increased attention as part of an effort to meet the challenges of congestion, air quality and quality of life [1]. In the recent years, many communities started promoting walkability concepts by educating the public about benefits of walking and by pressuring local authorities to improve facilities that serve non-motorized traffic [2].

Good pedestrian facilities promote people to walk, whilst poor ones discourage the use of area or structure where they are. This created the necessity of measuring the performance of pedestrian facilities in order to determine quality of operations, existing deficiencies, needs for improvements, and for purposes of priority settings. Traditionally, the quality of operations of transportation facilities is assessed on the basis of the level of service (LOS) concept. 
Therefore, evaluating the operating conditions of pedestrian flow by LOS is strategic for planning new facilities and for evaluating existing ones as well.

Assessing pedestrian LOS of existing facilities is useful to discover critical aspects and thus to define actions for improving them. Assessing pedestrian LOS of new facilities helps to discover any issues and to develop a proper and useful design. Undertaking a comfort assessment will identify any potential problems at an early stage. Mitigation measures can then be decided upon if required.

The paper has been structured in the following way: Chapter 2 presents an overview of more common and widely accepted methods for assessing pedestrian environment LOS; Chapter 3 focuses on group behavior in pedestrian flows; Chapter 4 presents the application of the HCM method for the evaluation of a selected site LOS. The calculation is based on collected measurements of pedestrian flow. Some critical issues and inconsistencies result. These have been reviewed and read taking into account the presence of groups in pedestrian flows. The empirical results are presented and commentated in Chapter 5. Conclusions follow.

\section{OVERVIEW OF PEDESTRIANSLOS METHODS}

A number of methods have been proposed for assessing quality of operations of pedestrian facilities on the basis of pedestrian Level of Service (LOS). Some of these methods utilize principles of vehicular traffic to evaluate pedestrian traffic operations. Other methodologies are more concerned with the facility design and walking environment than the actual pedestrian flows. A complete picture of LOS methodologies for the pedestrian facilities has been proposed by Sisiopiku [3] and Singh and Jain [4]. According to Singh and Jain, the current practices for evaluating pedestrian facilities can be grouped into two types:

A. Roadway Characteristics-Based Methods - Pedestrian Environment Factors: these methods are based on the characteristics of the walkways or pedestrian facilities. These methods use pedestrian perceptions and attempt to quantify the comfort level of pedestrians while encountering certain roadway characteristics.

B. Capacity-Based Methods - HCM 2000 [5] method: these methods use the principles of highway capacity which have been suitably adjusted to evaluate pedestrian facilities. They are helpful in planning pedestrian facilities but provide little information regarding acceptability by pedestrians.

Some of the more common and widely accepted methods for determining pedestrian LOS of above group A are reported in the following.

SCI Model or Landis method [6]: the model was developed through a multi-variable regression analysis based on observations. Independent variables that determine the LOS of safety (or comfort) include lateral separation elements between pedestrians and motor vehicle traffic, motor vehicle traffic mix, volumes, and speeds. The model and its pedestrian LOS predictions are based on perceived safety relative to traffic conditions and has not been correlated with actual safety data.

HCM 2010 presents a method to assessing Pedestrian LOS which is similar to the Landis method.

Australian Method [7] provides the opportunity to test the LOS provided by a pedestrian route and determines which factors contribute to low and high LOS. These factors were classified as design factors (path width, surface quality, obstructions, crossing opportunities), 
location factors (connectivity, path environment, potential for vehicle conflict) and user factors (pedestrian volume, mix of path users, personal security). Each factor is assigned a point on the basis of its presence and weights are assigned from the response ratings obtained from various stakeholders.

Dixon Method [8] The methodology is based on the hypothesis that there is a critical mass of variables that must be present to attract non motorized trips and defines a LOS rating that describes the degree to which facility provisions encourage pedestrian use. It considers mainly measures of pedestrian safety feature and does not take into account pedestrian flow; it is simple and easy but rather arbitrarily.

Trip Quality Method [9] combines urban design architectural principles with practical safety and capacity issues to define nine qualitative parameters (enclosure of walking path by building and surrounding environment, building articulation taking account buildings flow in relation to each other, complexity and transparency of spaces relating to the ability of a pedestrian to move from public to private space, overhangs/awnings/varied rooflines, shade trees, buffer, complexity of path network and physical components/condition). A score is assigned to each parameters and the average score is the LOS.

The most widely used method of group B is the HCM 2000 method by the Transportation Research Board. The method is based on the measurement of pedestrian flow rate and sidewalk space, density and speed. Pedestrian LOS is calculated by counting pedestrians who cross a point over a certain period of time (usually $15 \mathrm{~min}$ ), reducing that figure to pedestrians per minute and then dividing by the effective width of the sidewalk. The resulting figure is called the flow rate. The pedestrian flow rate, which incorporates pedestrian speed, density, and volume, is equivalent to vehicular flow. According to the HCM: "As volume and density increase, pedestrian speed declines. As density increases and pedestrian space decreases, the degree of mobility afforded to the individual pedestrian declines, as does the average speed of the pedestrian stream."

A planner may then look up the flow rate in a table to determine the pedestrian LOS grade. Like for vehicular flow HCM 2000 provides values of flow rate, speed, space or density, for each LOS from A to F. In particular, space M [mq/ped], which is the inverse of density, is a very significant measure for assessing LOS providing the availability of space for pedestrians.

The HCM 2000 methodology for pedestrian LOS measurement has tremendous advantages - it is relatively easy to collect data for its calculation, and the subsequent LOS is easy to calculate. The HCM 2000 methodology strives to provide a universal measurement, with an index comparable between places and times. But there are studies in the transportation planning and engineering field that show that the current HCM 2000 method of analyzing pedestrian LOS does not accurately reflect the complex pedestrian experience under some circumstances. Most importantly, the HCM 2000 method does not take into account many physical, environmental and psychological factors which affect the pedestrian walking experience [10].

A comparison of factors included in the pedestrian LOS assessment methods above mentioned is in the following Table 1.

\section{PEDESTRIANS GROUPS}

According to Canetti [11] work, the normal pedestrian behavior in a crowd is leaded by the fear to be touched principle: "There is nothing the man fears more than touch of the unknown ..... All distance which men place around themselves are dictated by this fear". 
Table 1: Comparison of factors included in pedestrian LOS assessment methods [3].

\begin{tabular}{|c|c|c|c|c|c|}
\hline Issue & HCM 2000 & $\begin{array}{c}\text { Landis - } \\
\text { HCM } 2010\end{array}$ & Australian & Dixon & Trip quality \\
\hline Geometry & $\begin{array}{l}\text { Pedestrian } \\
\text { space, } \mathrm{V} / \mathrm{C} \\
\text { ratio, width }\end{array}$ & $\begin{array}{l}\text { Motor path } \\
\text { width, on } \\
\text { street parking }\end{array}$ & Path width & $\begin{array}{l}\text { sidewalk } \\
\text { width, } \\
\text { off street/ } \\
\text { parallel } \\
\text { alternative, } \\
\text { barrier }\end{array}$ & $\begin{array}{l}\text { Pedestrian } \\
\text { path } \\
\text { components }\end{array}$ \\
\hline +Flow & $\begin{array}{l}\text { Pedestrian } \\
\text { flow and } \\
\text { speed }\end{array}$ & $\begin{array}{l}\text { Vehicle flow } \\
\text { and speed }\end{array}$ & $\begin{array}{l}\text { Pedestrian } \\
\text { volume; mix } \\
\text { of users }\end{array}$ & $\begin{array}{l}\text { Vehicle LOS, } \\
\text { travel lanes }\end{array}$ & $\begin{array}{l}\text { Not } \\
\text { considered }\end{array}$ \\
\hline Path & $\begin{array}{l}\text { Not } \\
\text { considered }\end{array}$ & $\begin{array}{l}\text { Sidewalk and } \\
\text { buffer widths }\end{array}$ & $\begin{array}{l}\text { Obstruction, } \\
\text { connectivity, } \\
\text { enviroment }\end{array}$ & $\begin{array}{l}\text { Route; } \\
\text { buffer, } \\
\text { lighting, } \\
\text { shade trees }\end{array}$ & $\begin{array}{l}\text { Route; buffer; } \\
\text { trees overangs }\end{array}$ \\
\hline $\begin{array}{l}\text { Veich } \\
\text { conflicts }\end{array}$ & $\begin{array}{l}\text { Not } \\
\text { considered }\end{array}$ & $\begin{array}{l}\text { Not } \\
\text { considered }\end{array}$ & $\begin{array}{l}\text { Potential for } \\
\text { conflicts; } \\
\text { crossing } \\
\text { opportunity }\end{array}$ & $\begin{array}{l}\text { Crossing } \\
\text { width, } \\
\text { driveway, } \\
\text { sidestreet, } \\
\text { ped signal }\end{array}$ & $\begin{array}{l}\text { Not } \\
\text { considered }\end{array}$ \\
\hline Security & $\begin{array}{l}\text { Not } \\
\text { considered }\end{array}$ & $\begin{array}{l}\text { Not } \\
\text { considered }\end{array}$ & $\begin{array}{l}\text { State of } \\
\text { security }\end{array}$ & $\begin{array}{l}\text { Not } \\
\text { considered }\end{array}$ & $\begin{array}{l}\text { Buffer, } \\
\text { transition to } \\
\text { other space }\end{array}$ \\
\hline $\begin{array}{l}\text { Support } \\
\text { facilities }\end{array}$ & $\begin{array}{l}\text { Not } \\
\text { considered }\end{array}$ & $\begin{array}{l}\text { Not } \\
\text { considered }\end{array}$ & Presence & $\begin{array}{l}\text { Not } \\
\text { considered }\end{array}$ & $\begin{array}{l}\text { Not } \\
\text { considered }\end{array}$ \\
\hline Quality path & $\begin{array}{l}\text { Not } \\
\text { considered }\end{array}$ & $\begin{array}{l}\text { Not } \\
\text { considered }\end{array}$ & Surface quality & $\begin{array}{l}\text { Lighting, } \\
\text { state of } \\
\text { maintenance }\end{array}$ & $\begin{array}{l}\text { Path } \\
\text { condition }\end{array}$ \\
\hline
\end{tabular}

Nevertheless, pedestrians often walk very closed each other violating that principle, it happens when pedestrians are part of a voluntary or involuntary group.

Involuntary groups arise due to signal control, geometrics, or when a large number of bus or subway riders exit onto the sidewalk. This phenomenon is called platooning. To account for the impact of platooning on pedestrian travel behavior, the HCM 2000 introduces the 'Platoon-Adjusted LOS Criteria for Walkways and Sidewalks', a table which can be used to obtain the platoon LOS. The HCM 2000 states that the LOS which occurs in platoons is generally one level poorer than that determined by average flow criteria. All the other methods mentioned in the previous chapter do not consider platooning effects.

The majority of pedestrians do not walk alone, but in social (voluntary) groups such as friends, couples, colleagues, families; they are willing to be in touch each other and Canetti 
defines that with the concept of crowd crystal. Up to $70 \%$ of observed pedestrians in a commercial street move in social (voluntary) groups [12]. It is possible to observe that voluntary groups present an internal dynamic. Integrants of the same group tend to unify their speed in relation to the speed of other in order to maintain the consistency of the group. In that sense if a member of a group walks slower for any reason, the probable speed of the group would be that integrant's speed, all the others adapting to this pace of walk.

So the pedestrians behavior seems very different in the voluntary group where people are close in order to communicate each other from the involuntary group where people are constrained to walk close each other. According to the HCM 2000 method, platoons need more space than individual pedestrians in order to perceive the same LOS. For voluntary groups it seems the opposite: people need less space than individual pedestrians in order to perceive the same LOS because the smaller range of distance enables communication amongst the different members of the group. The dimensions of the shared space become highly important for the internal groups dynamics: the distance between members varies from $0.5 \mathrm{~m}$ to $0.7 \mathrm{~m}[13,14]$.

\section{THE CASE OF STUDY - DATA COLLECTION AND ANALYSIS}

On 9th June 2015, starting from 3.00 pm, we collected data by Microsoft KinectV1 and a video camera with a top down view and a resolution of $30 \mathrm{frames} / \mathrm{s}$. The field study was a corridor (infinite) in a building of Massachusetts Institute of Technology, having width: $2.7 \mathrm{~m}$; effective width $2.2 \mathrm{~m}$. The area of study used to calculated the density is a rectangular shape delimited by vertices lines blue, having surface $S=4.9 \mathrm{~m}^{2}$; the section for measuring flow is a line in the middle of study area. The layout of the recording set up and study area are shown in the following Fig. 1.

The recording period is $27 \mathrm{~min}$ and the pedestrian behavior is natural, since the recording tools did not attract pedestrians attention.

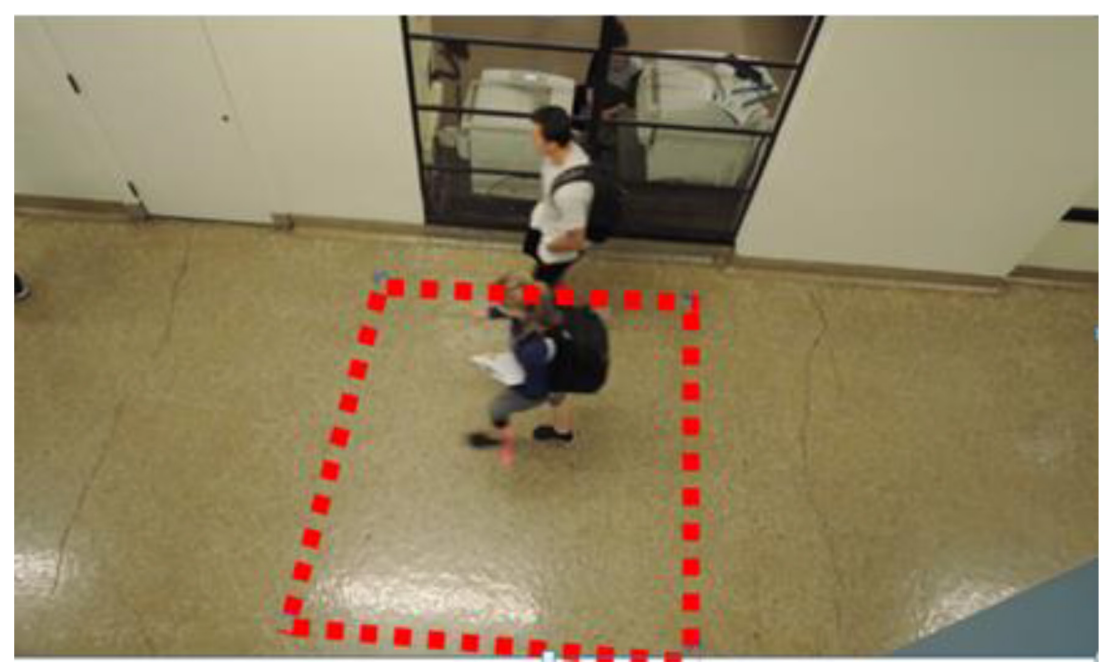

Figure 1: The pedestrian corridor and the rectangular shape. 
The Kinect sensor retrieves the position of the pedestrians every millisecond in a range of approximately 4 by $4 \mathrm{~m}$. The Kinect sensor is an infrared camera that works with time of flight technology. The collected data was first cleaned in order to erase errors and noise, and after processed with a script to obtain different indicators, among them the time and speed. This is a complementary process of the calculation developed with the video camera.

Processing the video recorded and elaborating the data collected for each pedestrian $i$ the followings data have been collected:

IDi: identification number of each pedestrian;

IDGRi: group identification number of each pedestrian belongs to;

TIi: time when pedestrian i completely (all two feet) enters in the study area;

TOi: time when pedestrian i completely (all two feet) exits out the study area;

TC $i$ : time when pedestrian $\mathrm{i}$ is the middle in the study area, this time is calculated as $0,5 \mathrm{x}$ (TOi - Tii), supposing constant speed ;

Diri: direction of pedestrian;

Geni: pedestrian gender (male or female);

$N i$ : number of pedestrian completely inside the study area at TCi (pedestrians of $N i$ are known);

The total number of pedestrians that crossed the area of study was 395 . The flow was equally distributed in the two directions: about $47 \%$ in a direction and about $53 \%$ in the opposite direction.

About $42 \%$ walked in voluntary groups and 58\% alone. As it concerns the group dimensions, the data are reported in Table 2: the $83 \%$ of the total number of pedestrians that walk in groups, belongs to a two-member group. The $10 \%$ of the total number of pedestrians that walk in groups, belongs to a three-member group and the 7\% of the total number of pedestrians that walk in groups, belongs to a four-member group. Almost $45 \%$ of the groups were composed by both the genders. Among the mono gender groups, we observed an equal number of female and male groups.

Figure 2 shows the cumulative number of pedestrians against time (s). Four periods each one characterized by a constant flow rate have been identified.

According to the HCM 2000 method, pedestrian LOS is mainly related to the space available for pedestrian $\mathrm{M}\left[\mathrm{m}^{2} /\right.$ ped], which is the inverse of the Density $\left[\mathrm{ped} / \mathrm{m}^{2}\right]$ and the speed V $[\mathrm{m} / \mathrm{s}]$. Therefore, analyzing the data above, for each pedestrian i the individual speed $V i[\mathrm{~m} / \mathrm{s}]$ and the related density $D i=(\mathrm{Ni} / \mathrm{S})\left[\mathrm{ped} / \mathrm{m}^{2}\right]$ have been assessed in according with Navin [15]. The density $D i$ is a function of the number of pedestrians in the rectangular shape at the time when the pedestrian i crosses the rectangular shape mid line.

The resulting 395 points $(V i, D i)$ have been plotted in Fig. 3. In the figure, the points that refer to pedestrian walking in social group have been marked with a diamond symbol whilst the points that refer to pedestrians walking alone have been marked with a star symbol.

Table 2: Observed data on voluntary group dimensions.

\begin{tabular}{lccc}
\hline N. groups. & Groups of 2 ped. & Groups of 3 ped. & Groups of 4 ped. \\
\hline 59 & $83 \%$ & $10 \%$ & $7 \%$ \\
$(132$ ped $)$ & $(49$ groups -98ped $)$ & $(6$ groups -18 ped $)$ & $(4$ groups -16 ped $)$ \\
\hline
\end{tabular}




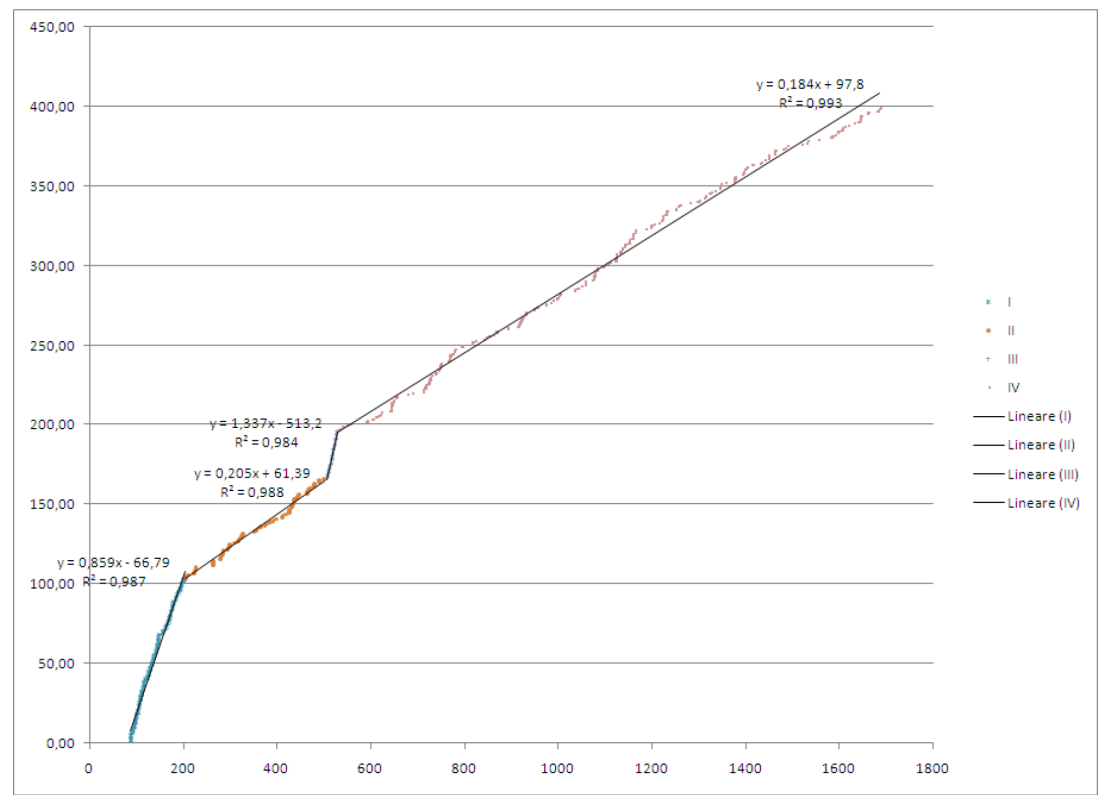

Figure 2: Cumulative number of pedestrian crossing corridor section Vs time [s].

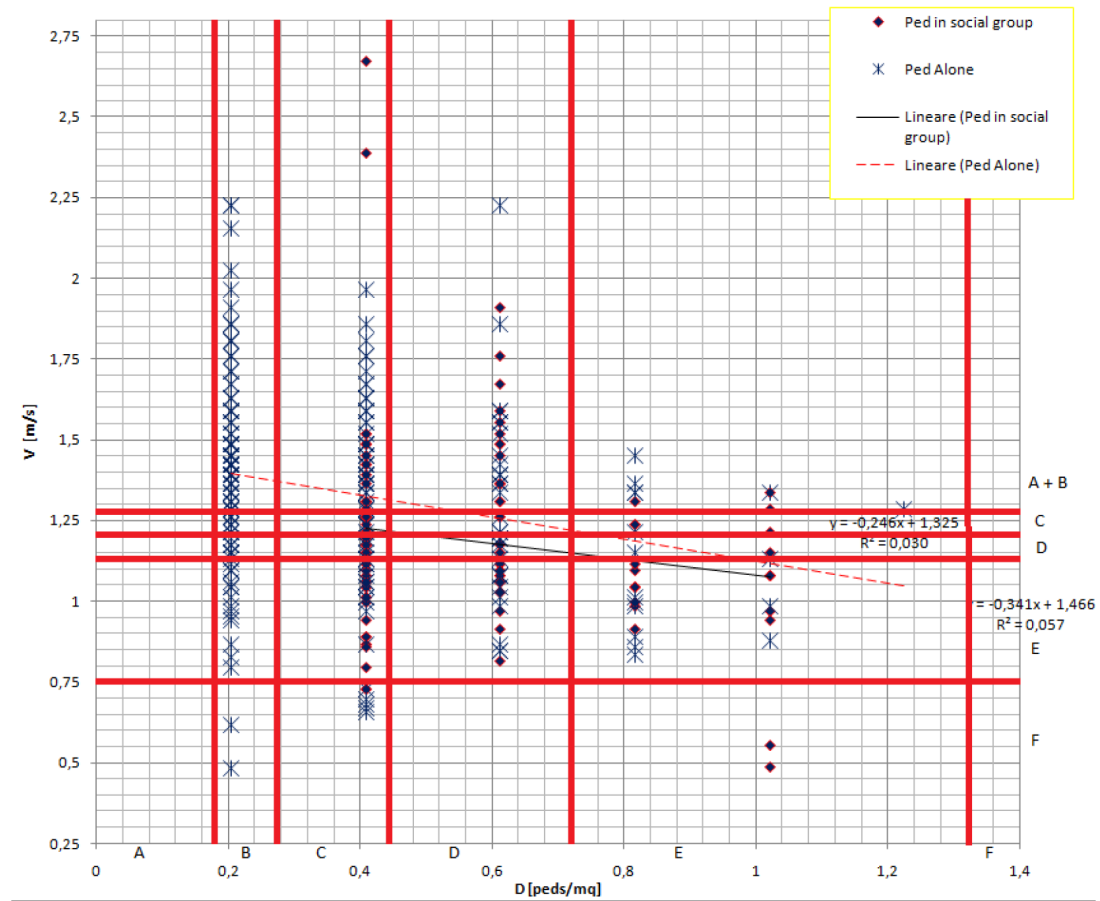

Figure 3: Speed Vs Density of pedestrian divided in alone and social groups. 


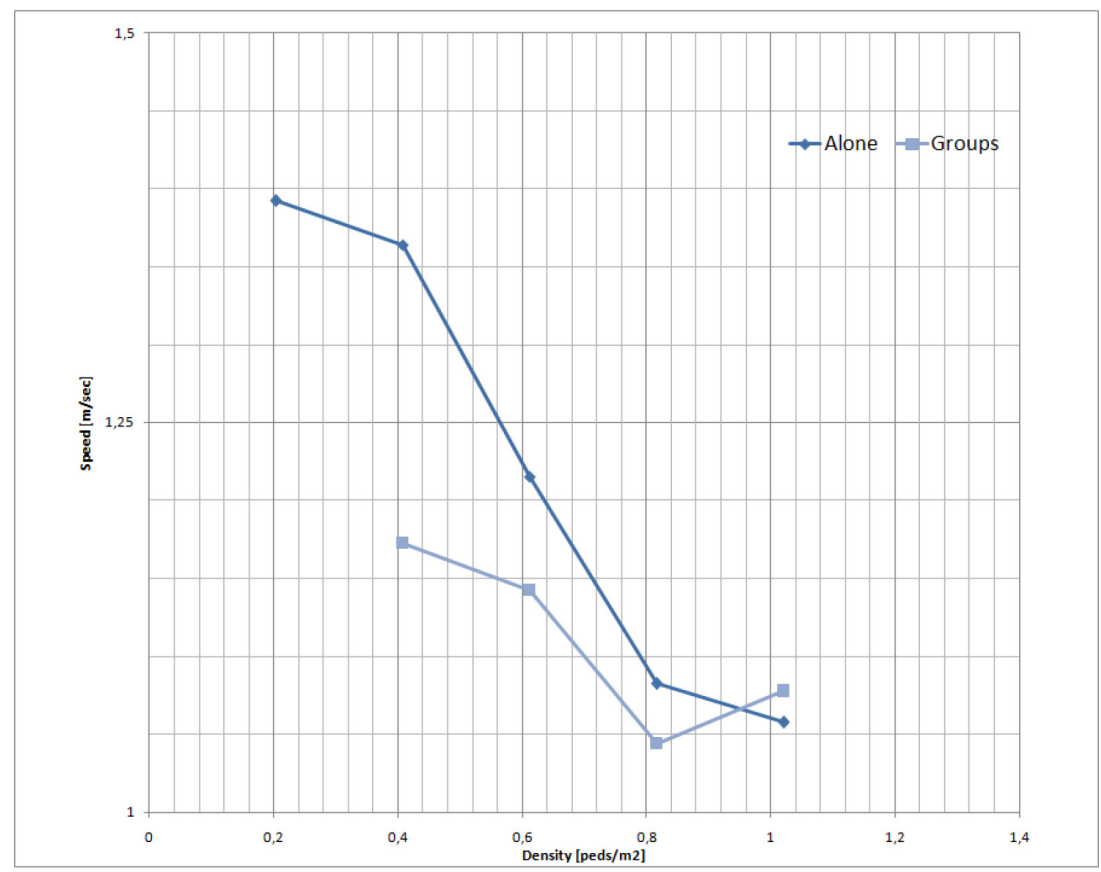

Figure 4: Median speed Vs. density for pedestrian alone and in social group.

For each density value, the median of the speeds of the individuals that crossed the rectangular shape in the given density conditions has been assessed and the resulting data are reported in Fig. 4.

In Figs 3, the LOS values are reported in relation to the speed and density values, according to HCM 2000 method.

\section{RESULTS}

Figure 3 shows a large pedestrian speed variation for each density value, both for groups and pedestrians walking alone.

As shown in Fig. 4, the speed of pedestrians walking alone decreases for higher density more than which of pedestrians walking in groups, further the speed of pedestrians walking in voluntary group tends to be lower than speed of pedestrians walking alone at same level of density, this does really not mean a lower perceived LOS of pedestrians in groups. On the other hand, when pedestrian walking in group (in no congestion case) the density tends to be higher because of people keep lower distance between each other to communicate better, but this does really not mean a lower perceived LOS as well.

In Fig. 3, only the 13\% of the points agrees with the HCM 2000 LOS assessment for both speed and density (or space), i.e. a point has LOS C both for speed and density, whilst forthe $87 \%$ of these points the LOS value assessed according to the speed value is different to the LOS value assessed according to the density value. Therefore, we define according the HCM 2000 method two different zones of points, I and II, where LOS levels areaggregated into two groups respectively acceptable or not acceptable, taking into account both prescriptions in term of speed and density. 


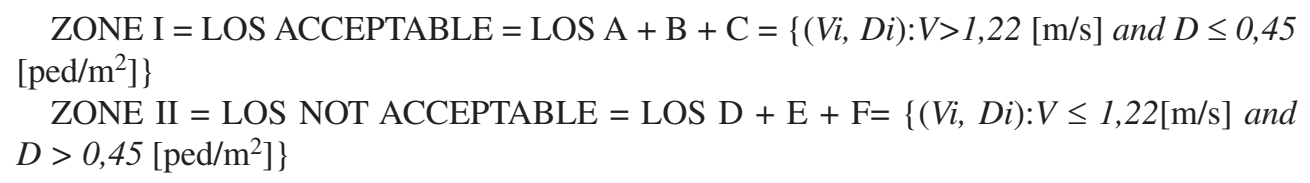

About the $36 \%$ of points do not belong neither zone I nor II, and therefore for these points the LOS assessed according to speed is very different from one according to density (i.e. for example a point having a speed $1,27, \operatorname{LOS} B$, and density 0.80 LOS D). Since about the $46 \%$ of these inconsistent points are member of voluntary groups, it is evident that the voluntary groups presence in pedestrian flow is critical and the current LOS assessment methods are not able to take them into account.

\section{CONCLUSIONS}

The paper presents evidence that the pedestrian flows are modified by groups and that the overall behavior of the crowd is affected by people clustering.

The HCM 2000, and other manuals as well, assume that the level of comfort of people is related to the area of space that people can use while they are walking. This measure is calculated for every individual present in that zone, yet it does not take into account groups. If there is a large number of people in the same area, the level of comfort is lower and according to the results there are variations on the speed that people can walk.

However, what if they want to use less space and regulate their speed because they voluntary decide to walk in a group? This idea makes explicit that some people are walking voluntarily in groups and that they are aware of the higher density and speed adjustments they have to cope with in order to keep walking in a group. In addition, a similar speed variation appears when there are more individuals than groups in a certain space. Therefore, this could signify that if individuals walking independently exhibit similar speed variations than groups even though they are not forced to move in a certain way, as slower or closer to each other to keep the consistency of the group, then this behavior does not depend on the presence of people clusters solely. It seems if individuals behave that way voluntarily then their speed is not affected by the presence of groups. In addition, it shows that the even though the density of a certain space is higher when groups are present this does not represent an 'uncomfortable' situation per se. The LOS measurement should cope with this idea of perhaps having a dynamic value for density measurement which might change depending of the presence of groups, incorporating in that way, a feature that is a fundamental in human walking.

\section{REFERENCES}

[1] Sisiopiku, V.P., Zhang, X. \& Virkler, M.R., Pedestrian level of service and quality of operations assessment methods. In Proceedings of the 81st Transportation Research Board Annual Meeting, Washington, D.C., 2002.

[2] Transport of London, Pedestrian comfort guidance for London, 2010, available at www. tfl.gov.uk/walking

[3] Sisiopiku, V., Byrd, J. \& Chittoor, A., Application of level of service methods for the evaluation of operations at pedestrian facilities. Transportation Research Record Journal of the Transportation Research Board, 2002(1), pp. 117-124, 2007. http://dx.doi.org/10.3141/2002-15

[4] Sing, K. \& Jain, P.K., Methods of assessing pedestrian level of service. Journal of Engineering Research and Studies, 2(1), pp. 116-124, 2011. 
[5] Highway Capacity Manual, National Research Council, Transportation Research Board, Washington, D.C., 2000.

[6] Landis, B.W., Vattikuti, V.R., Ottenberg, R.M., McLeod, D.S., Guttenplan, M., Modelling the roadside walking environment: a pedestrian level of service. Transportation Research Record 1773, TRB, National Research Council, Washington, D.C., pp. 82-88, 2001.

[7] Nicole Gallin, Quantifying Pedestrian Friendliness - Guidelines for Assessing Pedestrian Level of Service. Walking the 21st Century 20th to 22nd February 2001. Perth, Western Australia.

[8] Dixon, Linda, B., Bicycle and pedestrian level-of-service performance measures and standards for congestion management systems. Transportation research record 1538, TRB, National Research Council, Washington, D.C., pp. 1-9, 1996.

[9] Jaskiewicz, F., Pedestrian level of service based on trip quality. transportation research circular, national research council, transportation research board, Washington, D.C., 2000.

[10] Bloomberg, M.R. \& Burden, A.M.. New York city pedestrian level of service study phase i, nyc dcp transportation division April 2006, available at http://www.nyc.gov

[11] Canetti, E. \& Stewart, C., Crowds and power. 1984 Ferrar, Straus and Giroux.

[12] Moussaïd, M., Perozo, N., Garnier, S., Helbing, D. \& Theraulaz, G., The walking behavior of pedestrian social groups and its impact on crowd dynamics. PLOS ONE, 5(4), p. e10047, 2010. http://dx.doi.org/10.1371/journal.pone.0010047

[13] Cepolina, E.M., Cervia, S. \& Gonzalez Rojas, P., Pedestrian modelling: autonomy and communication needs. Proceedings of the International. Conference on Harbor Maritime and Multimodal Logistics M\&S, ISBN 978-88-97999-58-4; Bruzzone, Del Rio Vilas, Longo, Merkuryev, Piera Eds, 2015.

[14] Cepolina, E.M., Caroti, G., Piemonte, A. \& Gonzalez Rojas, P., Pedestrian modelling: discomfort assessement. Proceedings of the International Conference on Harbor Maritime and Multimodal Logistics $M \& S$, eds A.G. Bruzzone, D. Del Rio Vilas, F. Longo, Y. Merkuryev \& M.A. Piera, 2015.

[15] Navin, F.P.D. \& Wheeler, R.J., Pedestrian flow characteristics. Traffic Engineering, 19(7), pp. 30-36, 1969. 